\title{
Real-world experience of using basal insulin analogues in children with type 1 diabetes: is twice-daily dosing of insulin detemir justified? \\ Doświadczenie w stosowaniu analogów jako insuliny bazowej u dzieci z cukrzycą typu 1: czy jest uzasadnione dawkowanie insuliny detemir dwa razy na dobę?
}

\author{
Devi Dayal, Latika Rohilla
}

Endocrinology and Diabetes Unit, Department of Paediatrics, Postgraduate Institute of Medical Education and Research, Chandigarh, India

\section{Dear Editor,}

Insulin glargine (iGla) and detemir (iDet) are the two most commonly used basal insulins in basal-bolus regimens in type 1 diabetes (T1D) [1]. While both these analogues have similar onset of action, their duration of effect has remained a matter of intense debate [1]. Under steady-state conditions, the mean duration of action of iGla is 24-25.6 hours and that of iDet is 21.5 hours [1]. Consequently, a higher proportion of patients are prescribed a twice-daily dosing of iDet as compared to iGla for a full basal coverage [1]. In addition to the concerns regarding the last few hours of the iDet action, twice-daily dosing also results in increased costs and hence its limited use in resource-poor settings. Unfortunately, most of the studies on the efficacy and action duration have compared either of the insulin analogues with NPH, and head-to-head iGla-iDet comparisons are limited [2-4]. In particular, it is unknown whether there is really a waning of effect of iDet during the last few hours of its action duration in daily clinical practice, which would justify its twice-daily dosing.

Self-monitored blood glucose (SMBG) records of the last three months in 22 randomly selected children with T1D (11 each using iDet and iGla in once-daily bedtime dosing) were compared. In addition, the mean $\mathrm{HbA}_{1 \mathrm{c}}$, mean daily total, and basal and mealtime bolus insulin doses were calculated. All patients were using either aspart or lispro as bolus insulin. We presumed that if the iDet effect really wanes, the required doses of evening insulin bolus might be higher in patients using iDet.

The mean age of the two groups of patients was similar ( $8.9 \pm 4.7$ vs. $8.3 \pm 4.8$ years, respectively). Five children in the iGla group and four in the iDet group were pubertal. The mean duration of diabetes was $3.2 \pm 2.3$ years. In the iGla group, four (36\%) families belonged to lower, five (45\%) to middle, and two (18\%) to upper socioeconomic status (SES). The iDet group had three (27\%), five (45\%), and three (27\%) families in the lower, middle, and upper SES, respectively. The parents' educational levels were also similar in the two groups. The glycaemic parameters, episodes of hypoglycaemia, and the requirement of daily basal and bolus insulin doses were also similar in the two groups (Table I).

These results indicate a similar efficacy of both basal analogues when used in once-daily dosing in routine clinical practice and are consistent with our previous studies in children with T1D [2, 3]. The common belief amongst physicians that a twice-daily dosing is required in a substantial proportion of patients who are on iDet could not be ascertained in this small study [1]. The basis of such belief, however, is not supported by available literature. There are a limited number of studies on head-to-head comparison of iDet and iGla in patients with T1D $[4,5]$. All the comparison studies conducted on patients with either T1D or type 2 diabetes (T2D) also used once-daily dosing of these two basal insulin analogues and demonstrated similar efficacy [5-7]. In the only available trial that compared once- versus twice-daily iDet in patients with T1D, the HbA1c at four months was $8.1 \pm 0.9$ vs. $8.0 \pm 1.0 \%$ with once- and twice-daily iDet, respectively, with an adjusted between-group difference of $0.12 \%$, showing noninferiority for once-daily dosing [8]. This study concluded that the most suitable routine starting schedule for iDet is once-daily injection in a basal-bolus regimen for T1D [8]. The findings were the same in another study that compared once- and twice-daily iDet dosing in T2D [9]. A recent meta-analysis that included mainly observational studies generally considered closer to the "realworld" situation also did not indicate favouring a twice-daily administration of iDet [4].

A similar requirement of pre-dinner bolus insulin doses in both groups indicates that the effect of once daily iDet remained similar to iGla during the last few hours of its 24-hour action. This finding assumes importance in view of the recently described "dusk phenomenon" characterised by unexplained pre/post-dinner hyperglycaemia in patients with diabetes [10]. Although the underlying mechanisms are unknown, one of the ways suggested to overcome this phenomenon is to increase the basal insulin

Received: 15.12 .2018

Accepted: 15.03.2019

Conflict of interests: none declared.
Prof. Devi Dayal

Endocrinology and Diabetes Unit Department of Paediatrics

Advanced Paediatrics Center

Postgraduate Institute of Medical

Education and Research
Chandigarh-160012, India Tel. 0091-172-2755315 (O) 0091-172-2772777 (R)

Fax 0091-172-2744401; 2745078 E-mail: drdevidayal@gmail.com; dayal.devi@pgimer.edu.in
103 
supply in patients using insulin pumps, indirectly indicating an increased requirement of the evening insulin [10]. This also would have meant an increased requirement of pre-dinner insulin in our patients using iDet if we presumed that the iDet effect wanes during last few hours of its daily profile. Additionally, in our extensive experience of using basal insulin analogues, we have never used iDet in twice-daily dosing [2, 3]. We suggest conducting larger studies comparing iGla with iDet as well as once- versus twice-daily dosing of iDet in real-life clinical practice. Until then, the treating physicians may consider using iDet as once-daily dosing only in children with T1D.

Table I. Comparison of glycaemic parameters, hypoglycaemic events, and insulin doses of patients treated with insulin glargine and insulin detemir

\begin{tabular}{|c|c|c|c|c|}
\hline Variable & & $\begin{array}{l}\text { Glargine group } \\
\text { Mean (SD) }\end{array}$ & $\begin{array}{l}\text { Detemir group } \\
\text { Mean (SD) }\end{array}$ & $p$-value \\
\hline \multirow[t]{4}{*}{ Blood glucose } & Before breakfast & $148.40(86.54)$ & $129.84(59.14)$ & 0.56 \\
\hline & Before lunch & $156.80(79.97)$ & $170.10(79.14)$ & 0.69 \\
\hline & Before dinner & $163.72(87.13)$ & $167.72(79.13)$ & 0.91 \\
\hline & At Bedtime & $158.87(92.35)$ & $162.81(76.04)$ & 0.91 \\
\hline \multirow{4}{*}{$\begin{array}{l}\text { Hypoglycaemic episodes per } \\
\text { month }\end{array}$} & Asymptomatic & $1.81(0.40)$ & $1.63(0.50)$ & 0.36 \\
\hline & Symptomatic & $0.63(0.50)$ & $0.81(0.60)$ & 0.45 \\
\hline & Severe symptomatic & $0.18(0.40)$ & $0.09(0.30)$ & 0.55 \\
\hline & Nocturnal & $0(0)$ & $0(0)$ & \\
\hline $\mathrm{HbA}_{1 \mathrm{c}}$ & & $7.88(1.25)$ & $7.57(1.03)$ & 0.53 \\
\hline Basal insulin dose (U/kg/day) & & $0.231(0.41)$ & $0.371(0.13)$ & 0.29 \\
\hline Bolus insulin dose (U/kg/day) & & $0.488(0.51)$ & $0.620(0.28)$ & 0.46 \\
\hline Before breakfast bolus ( $\mathrm{U} / \mathrm{kg} / \mathrm{day})$ & & $0.172(0.40)$ & $0.206(0.09)$ & 0.78 \\
\hline Before lunch bolus (U/kg/day) & & $0.178(0.29)$ & $0.221(0.10)$ & 0.64 \\
\hline Before dinner bolus (U/kg/day) & & $0.141(0.06)$ & $0.190(0.10)$ & 0.17 \\
\hline
\end{tabular}

\section{References}

1. Mathieu C, Gillard P, Benhalima K. Insulin analogues in type 1 diabetes mellitus: getting better all the time. Nat Rev Endocrinol 2017; 13: 385-399. doi: 10.1038/nrendo.2017.39

2. Saini A, Devidayal, Verma S, Bhalla AK. Comparative efficacy of once daily insulin glargine with twice daily NPH insulin in children with type 1 diabetes. J Diabetes Metab 2011; 2: 124.

3. Dayal D, Sharma S, Sachdeva N, et al. Efficacy of insulin detemir compared to insulin NPH on glycemic control in Indian children with type 1 diabetes. J Diabetol 2014; 5: 3.

4. Silva TBC, Almeida PHRF, Araújo VE, et al. Effectiveness and safety of insulin glargine versus detemir analysis in patients with type 1 diabetes: systematic review and meta-analysis. Ther Adv Endocrinol Metab 2018; 9: 241-254. doi: 10.1177/2042018818781414
5. Heller S, Koenen C, Bode B. Comparison of insulin detemir and insulin glargine in a basal-bolus regimen, with insulin aspart as the mealtime insulin, in patients with type 1 diabetes: a 52-week, multinational, randomized, open-label, parallel-group, treat-to-target noninferiority trial. Clin Ther 2009; 31: 2086-2097. doi: 10.1016/j.clinthera.2009.10.006

6. Zhang T, Lin M, Li W, et al. Comparison of the efficacy and safety of insulin detemir and insulin glargine in hospitalized patients with type 2 diabetes: A Randomized Crossover Trial. Adv Ther 2016; 33: 178-185. doi: 10.1007/s12325-016-0288-7.

7. Galindo RJ, Davis GM, Fayfman M, et al. Comparison of efficacy and safety of glargine and detemir insulin in the management of inpatient hyperglycemia and diabetes. Endocr Pract 2017; 23: 1059-1066. doi: 10.4158/EP171804.OR.

8. Le Floch JP, Lévy M, Mosnier-Pudar H, et al. Comparison of onceversus twice-daily administration of insulin detemir, used with meal- 
time insulin aspart, in basal-bolus therapy for type 1 diabetes: assessment of detemir administration in a progressive treat-to-target trial (ADAPT). Diabetes Care 2009; 32: 32-37. doi: 10.2337/dc080332.

9. Cander S, Dizdar OS, Oz Gul O, et al. Comparison of efficacy and safety of once- versus twice-daily insulin detemir added on to oral antidiabetics in insulin-naive type 2 diabetes patients: 24-week, crossover, treat to target trial in a single center. Prim Care Diabetes 2014; 8: 256-264. doi: 10.1016/j.pcd.2014.01.010.

10. Du S, Shi MJ, Sun ZZ, Li W. Clinical diagnosis for dusk phenomenon of diabetes. Medicine (Baltimore) 2018; 97: e11873. doi: 10.1097/MD.0000000000011873 
